\title{
Risk and uncertainty in financial markets: a symposium
}

\section{Jens Beckert ${ }^{1, *}$ and Hartmut Berghoff ${ }^{2}$}

${ }^{1}$ Max Planck Institute for the Study of Societies, Cologne, Germany;

${ }^{2}$ German Historical Institute, Washington DC, USA.

*Correspondence: beckert@mpifg.de

Economic action takes place in risky and uncertain environments. Whether for medieval traders whose merchandise needs to be secured against theft during transport or financial traders on Wall Street who need to close deals in highly volatile financial markets_ risk and uncertainty are universal features of economic activity. The question of how societies and economic actors deal with risk and uncertainty provides a crucial entry point for investigating the economy.

In capitalist economies, uncertainty is paramount. In parts it arises from competition because the profitability of investments depends on the unknown activities of other market actors. One way in which companies and states react to these risks is by attempting to limit or regulate competition. These efforts range from the strictly enforced rules of closed shops such as guilds through to import restrictions, the exclusion of specific social groups from market access and forms of monopolistic competition through product differentiation. Uncertainty arises also from asymmetrically distributed information or unknown qualities of commodities. Uncertainty has a further source in the freedom of cooperation partners in exchange relations. Due to information asymmetries, all joint economic activity for both production and exchange involves trust, a trust that can be broken. Actors must succeed in integrating their plans despite often diverse interests and decisions that involve incalculable future developments. Economic organization must provide safeguards for contract partners in order to instill in them a willingness to engage in economic exchange. Such safeguards can be social norms, institutions for the enforcement of property rights and families or closed ethnic networks with high sanctioning powers.

The sources of uncertainties economic actors confront can be classified in three categories: (i) strategic uncertainty that refers to the dependence of 
economic success on the actions of other actors pursuing their own interests. This problem of double contingency is pervasive in all contractual agreements which are incomplete, that is, which leave discretion to the exchange partners. (ii) Uncertainty originating from contingent assessments of the value of goods in the market. Examples of this category occur in financial markets where quality and price is the outcome of interpretation into the risks associated with a financial asset. (iii) Uncertainty stemming from events occurring in the future that are unknown to actors in the present due to the openness of the future.

It can be assumed that these issues are relevant in all economic systems and have existed throughout economic history. Capitalistic economies, however, are characterized by a specific tension between those institutions reducing uncertainty and those institutions creating uncertainty, especially markets. Uncertainty creates problems for the coordination of economic activities and causes insecurity for actors, but it is also a crucial source of opportunities for profit. The position actors take to reduce or expand uncertainty in the economy also depends on their class situation (Max Weber).

Economic actors must make decisions that depend on an uncertain future. How do economic actors deal with uncertainty? How do they transform uncertainty into calculable risks? How do they avoid complete blockades or the breakdown of markets? Risks have to be moderated, insured or ignored to keep the economy functioning. The uncertainties of economic exchange are resolved differently in different economic configurations. The specific responses to these challenges depend on cultural influences, power structures, the fabric of social networks and the systemic properties of the economic and political regime. Societies find widely differing ways to deal with the uncertainties actors confront in the economy, differences which are reflected in the institutional and social structures as well as in the normative and cognitive orientations.

In this symposium, two sociologists and one economic historian address some of these issues, focusing on financial markets.

Bruce Carruthers discusses the relationship of risk and uncertainty using the example of credit ratings by specialized commercial agencies. He examines how uncertainty is transformed into risk. Decision-making on credit is fraught with uncertainty, and credit rating was invented in the 19th-century in the USA to help make credit uncertainty more tractable. Credit rating methods spread widely, even before their accuracy or efficacy had been generally accepted. The origins of credit rating reveal problems and limitations that re-emerged during the financial crisis of 2008, a time when rating agencies performed very poorly.

Alexander Engel discusses fundamental principles of future exchanges. These institutions depict themselves as suppliers of risk management services and it is textbook knowledge that futures markets exist to help those who want to dispose of price risks (hedgers) by bringing them together with those who want to take on 
the risks (investors/speculators). Engel challenges this idea in two ways. First, futures exchanges were not established to provide risk management services to the public. The notion of risk, which takes center stage in current interpretations, only slowly entered the debate. Secondly, Engel argues that the introduction of futures markets has actually increased overall individual exposure to price risk, while the exact form and structure of such exposure can now be chosen with more deliberation. Futures markets have enabled a more active approach towards risk; they have facilitated the emergence of a 'risk economy' in which risk itself has become a key commodity.

Richard Swedberg addresses the issue of confidence in financial markets. Confidence plays a crucial role in the work of John Maynard Keynes to explain economic stability and crisis. Once market actors have lost confidence in a company or in the state, the value of stocks or bonds will plummet. This is exactly what happened in the financial crisis of 2008 and the subsequent, and still unresolved, sovereign debt crisis in Southern Europe. Analyzing the financial crisis of 2008 and 2009 in the USA, Swedberg is interested in the questions of what confidence exactly is, how it is destroyed, and how it can be restored. He discusses confidence based on the work of Walter Bagehot. He defines confidence as an actor's readiness to base his or her decision to act, not on the best available information about the state of affairs (because the actor is unable to obtain it), but instead on proxy signs that signal what the state of affairs might be. Confidence suddenly evaporates if hidden losses are discovered.

The three articles assembled in this symposium discuss uncertainty in financial markets from different perspectives. The topic of uncertainty, and the provisions through which action in the economy is organized despite uncertainty, is a crucial topic for economic sociologists and economic historians. Although the topic is central not only to the financial markets that are the focus of this symposium, such markets do offer especially rich research opportunities to further our understanding of the social and political responses to uncertainty. 